\title{
Determination of the Material Properties of the Reinforcement for Textile-Reinforced Concrete Elements
}

Sergej Rempel ( $\square$ sergej.rempel@hs-augsburg.de)

Augsburg University of Applied Sciences

Marcus Ricker

University of Applied Sciences Biberach

Tânia Feiri

University of Applied Sciences Biberach

\section{Research Article}

Keywords: Textile-reinforced concrete, AR-glass reinforcement, Standardised tensile test for fibre strands, Design provisions, Carbon reinforcement, Carbon concrete

Posted Date: July 13th, 2021

DOI: https://doi.org/10.21203/rs.3.rs-666335/v1

License: (9) This work is licensed under a Creative Commons Attribution 4.0 International License. Read Full License 


\title{
Determination of the material properties of the reinforcement for textile-reinforced concrete elements
}

\section{Sergej Rempel ${ }^{1, *}$, Marcus Ricker $^{2}$ and Tânia Feiri $^{3}$}

${ }^{1}$ Hochschule Augsburg, University of Applied Sciences, An der Hochschule 1, Augsburg 86161, Germany; sergej.rempel@hs-augsburg.de

2 Institute of Structural Engineering, Hochschule Biberach University of Applied Sciences, Karlstraße 11, Biberach 88400, Germany; ricker@hochschule-bc.de

3 Institute of Structural Engineering, Hochschule Biberach University of Applied Sciences, Karlstraße 11, Biberach 88400, Germany; feiri@hochschule-bc.de

* Correspondence: sergej.rempel@hs-augsburg.de; Tel.: +49-821-5586-3637

\begin{abstract}
Textile-reinforced concrete has emerged in recent years as a new and valuable construction material. The design of textile-reinforced concrete requires knowledge on the mechanical properties of different textile types as well as their reinforcing behaviour under different loading conditions. Conventional load-bearing tests tend to be complex, timeconsuming, costly and can even lack consistent specifications. To mitigate such drawbacks, a standardised tensile test for fibre strands was developed aiming at characterising the material properties needed for the design of a textile-reinforced concrete component. For the sake of this study, an epoxy resin-soaked AR-glass reinforcement was considered. The standardised tensile test uses a fibre strand with $160 \mathrm{~mm}$ length, which shall be cut out of a textile grid. The results show that the textile reinforcement has a linear-elastic behaviour, and the ultimate tensile strength can be statistically modelled by a Gumbel distribution. Furthermore, the results indicate that the modulus of elasticity is not influenced by the length or the number of fibre strands. Therefore, the mean value from the standardised test can be used for the design purpose. These findings are essential to derive an appropriate partial safety factor for the calculation of the design values of the tensile strength and can be used to determine the failure probability of textile-reinforced concrete components.
\end{abstract}

Keywords: Textile-reinforced concrete; AR-glass reinforcement; Standardised tensile test for fibre strands; Design provisions; Carbon reinforcement; Carbon concrete 


\section{Introduction}

Textile-reinforced concrete is an innovative composite material that uses mesh-like reinforcements made of, for example, alkali-resistant glass (AR-glass), carbon or basalt. In contrast to ordinary steel reinforcements, textile reinforcements do not corrode. Therefore, concrete covers can be minimised, enabling the design and construction of slender concrete components. Such benefits promoted the emergence of the term "carbon concrete" for textilereinforced concrete components [1-3]. Recent developments show that some of the most favourable mechanical properties of carbon reinforcement, namely the high tensile strength and durability, have contributed to the growing acceptance of textile-reinforced concrete across the construction sector [4-12]. An example is the world's first carbon concrete bridge in Ebingen (Germany) [13].

Normally, building owners need an individual approval (e.g., the "ZiE" in Germany) or a general approval (e.g., the European Technical Assessments) for the production and construction of textile-reinforced concrete structures. These approvals are the only means to attain a proof of usability for the proposed textile-reinforced concrete component [14]. Thus, it is common that building authorities request extensive load-bearing tests to evaluate the ultimate limit state (ULS) and the serviceability limit state (SLS). These tests tend to be complex, time-consuming, costly, and can even lack consistent specifications [15-17]. Hence, provisions that support the design of structural components without further experimental testing would be valuable to designers - and ultimately, to the overall structural engineering community.

Kulas and Rempel [18] proposed a promising modelling approach for the bending design, which hardly differs from the conventional calculation for steel-reinforced concrete. The difference lays in the mechanical behaviour of distinct textile reinforcements. As opposed to steel reinforcement, AR-glass or carbon reinforcement has a linear-elastic behaviour without a pronounced yield plateau and has a 3 to 7 times higher ultimate tensile strengths [15-16]. Based on such mechanical properties, a standardised tensile test for fibre strands was proposed by [19]. It is relevant to highlight here that, normally, multiple fibres form a filament and multiple filaments compose a strand [20]. By using the above-mentioned standardised tensile test, the results can be used to determine the design values for a textile reinforcement, as epoxy resin-soaked AR-glass reinforcement. These values refer to the statistical parameters of two relevant materials properties: (1) ultimate tensile strength and (2) modulus of elasticity. Such parameters are fundamental for the assessment of safety levels 
(also known as reliability analysis) (e.g., [18, 21-22]) and for the calculation of partial safety factors.

This paper discusses the derivation of the statistical parameters for an epoxy resin-soaked AR-glass textile through the above-mentioned standardised tensile test. The test can be used for all epoxy resin-soaked fibre strands with a linear-elastic behaviour. The article is structured as follows: Firstly, the experimental setting is described including the procedures to analyse the influence of the length and number of fibre strands. Then, the test results are presented and discussed, following a reflection on their usability. Finally, the conclusions and limitations of this study are addressed. The results of the experimental campaign presented in this paper were originally described in a German publication [15].

\section{Carrying out the experiment}

\subsection{Standardised tensile test for fibre strands}

A standardised tensile test was developed to determine the behaviour of textile reinforcement of an epoxy resin-soaked AR-glass textile [19]. The test setup is schematically illustrated in Figure 1a. The procedure starts with individual fibre strands being cut out of the soaked and cured textile layers placed in a textile grid (Figure 1b). More precisely, a fibre strand with a length of $160 \mathrm{~mm}$ is cut out of the textile grid and a load is introduced through clamping jaws. This setup has the advantage that the influences of the scrim setup on the material parameters are considered during the test. The material properties of an individual fibre are not significant for the dimensioning since the textile properties are influenced by the production processes. In addition to the load measurement, the strain is registered with a strain gauge (extensometer) over a length of $100 \mathrm{~mm}$. During the test, the fibre strand may break prematurely near the loading point. In such cases, the ultimate tensile strength of the fibre strands is not fully reached, and therefore, the individual value must not be considered. In most tensile tests, the extensometer shall be removed shortly before failure to prevent damage to the transducer. Alternatively, the strain can be measured with an optical measuring device. However, the follow-up evaluation of the results can be rather complex [18]. 
a)

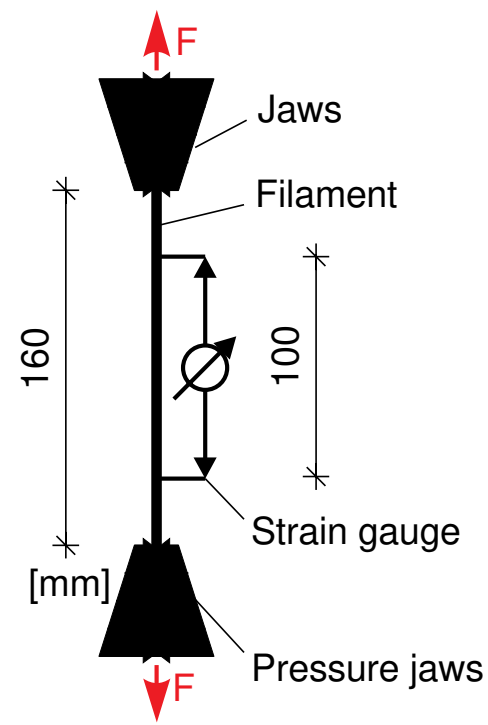

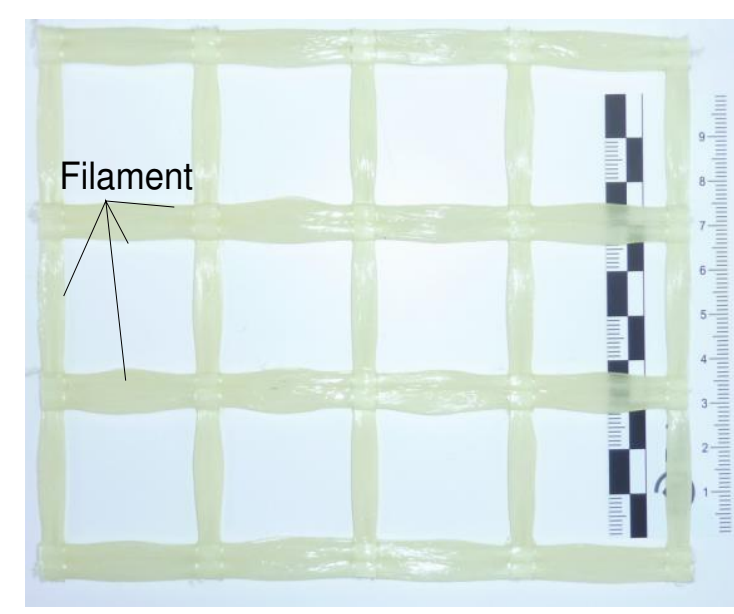

b)

Fig. 1 (a) Standardised tensile test set-up [18]. (b) Picture of the testing grid of AR-Glass reinforcement [15]

The above-described setup may be only used for fibre strands in which the load is transmitted through a stiff impregnation as it is the case of epoxy resin-soaked textiles. With these completely soaked fibre strands, the ultimate tensile strength, the modulus of elasticity obtained through the standardised tensile tests and the tests on composite components are similar (see Section 3.3). For this reason, the material parameters can be assessed on a pure fibre strand with a clamping device, and then, transferred to a composite component. In the case of unimpregnated or partially impregnated fibre strands, the load is transferred through the friction between the inner fibre strands. The transversal pressure of the clamping jaws increases the frictional stress so that more strands are directly involved in the transfer. As a result, the tensile stresses obtained in the textile by means of a standardised tensile test are higher than those obtained, for example, through a bending test.

Normally, to determine a meaningful probability density function for the ultimate tensile strength of the textile reinforcement, multiple standardised tensile tests are required. For this purposes, additional tests were conducted by industry partners. To avoid biased results, the test procedures were defined in advance alongside the collaborative setting between the partners. The test results were recorded in a shared database.

\subsection{Influence of the length of the fibre strand}

The standardised tensile test was used to investigate the influence of the length of the fibre strand. During the test, the lengths evaluated increased gradually for four times: It 
started with a length of $60 \mathrm{~mm}$, followed by a length of $160 \mathrm{~mm}$, a length of $320 \mathrm{~mm}$, and finally, it was considered a length of $640 \mathrm{~mm}$.

\subsection{Influence of the number of fibre strands}

To investigate the influence of the number of fibre strands on the ultimate tensile strength of the textile reinforcement, fibre strands must be stressed uniformly. An additional requirement is that several fibre strands must be drawn at the same time. However, this is not possible with the proposed standardised tensile test. For this reason, the tensile test shown in Figure 2 was carried out. In contrast to the standardised tensile test, the tension load was not directly applied on a strand, but instead on a reinforced concrete body. The load was transferred from the testing machine to the composite member through the pressure jaws. This procedure ensured that the fibre strands were evenly loaded. In addition to the load, the strain was also recorded with linear variable differential transformers (LVDTs) over a reference length of $450 \mathrm{~mm}$. This experimental setup is based on the RILEM recommendations [22]. A total of seven tensile test series were conducted on composite members reinforced with different numbers of fibre strands. To ensure that the ratio of the concrete cross-sectional area and the fibre strands remained roughly the same, the width $b$ and the thickness $h$ of the tensile specimen were adjusted. In addition, the standardised tensile tests on the fibre strands were conducted to show the transferability from a pure tensile test to a uniaxial tensile test of the composite material textile-reinforced concrete. 


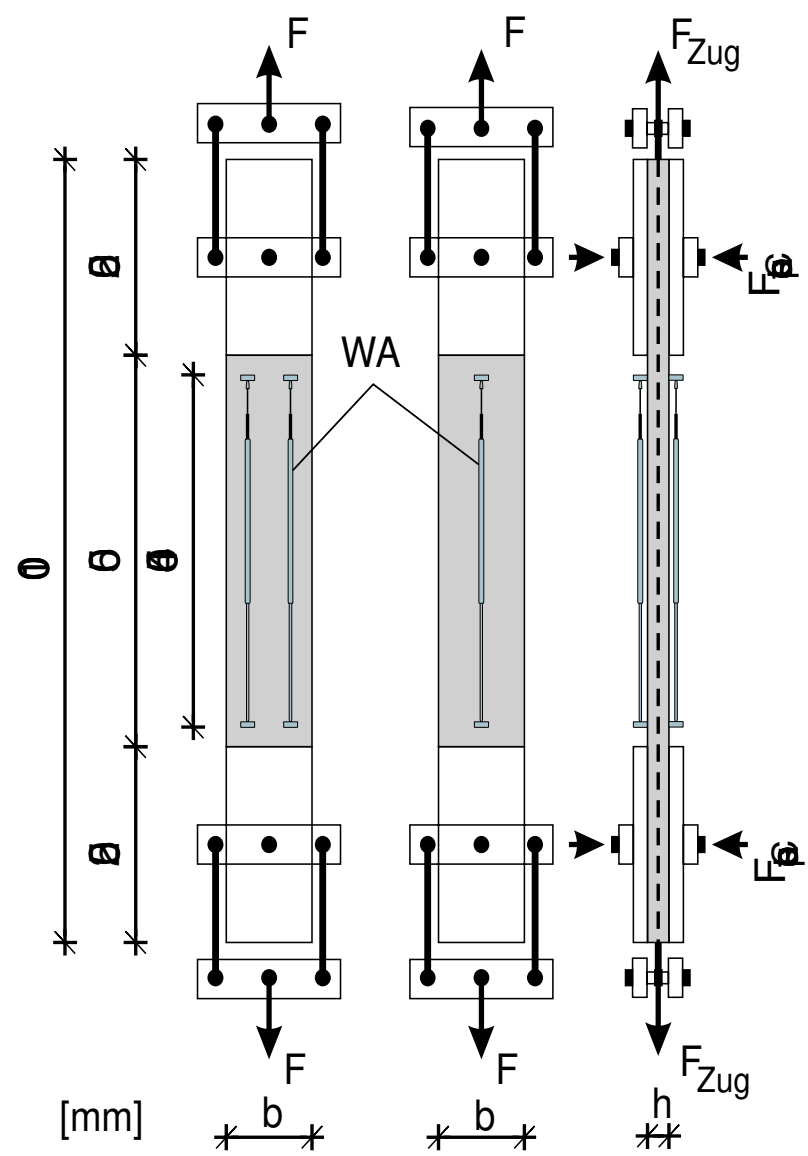

Fig. 2 Schematic representation of the uniaxial tensile test of the composite material in textile reinforced concrete [15]

\section{Experimental results}

\subsection{Standardised tensile tests on fibre strands}

\subsubsection{Material parameters for the design}

The results of the standardised tensile tests are shown in the stress-strain diagram in Figure 3a. An idealised stress-strain relationship is derived from the measurements, which can be later used for cross-sectional design of a textile-reinforced concrete component. The black curve represents the mean course of the individual experiments, which are indicated in grey. The dashed line in the figure refers to the idealised stress-strain relationship. The textile stress $\sigma_{\mathrm{t}}$ is calculated from the measured force $F$ and the accumulated fibre strands cross sectional area $A_{\mathrm{r}}$ according to Equation 1.

$$
\sigma_{\mathrm{t}}=\frac{\mathrm{F}}{A_{\mathrm{r}}}
$$


The lines show an almost linear-elastic course until the failure point. This confirms the assumption that the fibre strands are practically stretched and are hardly influenced by the knitting thread.
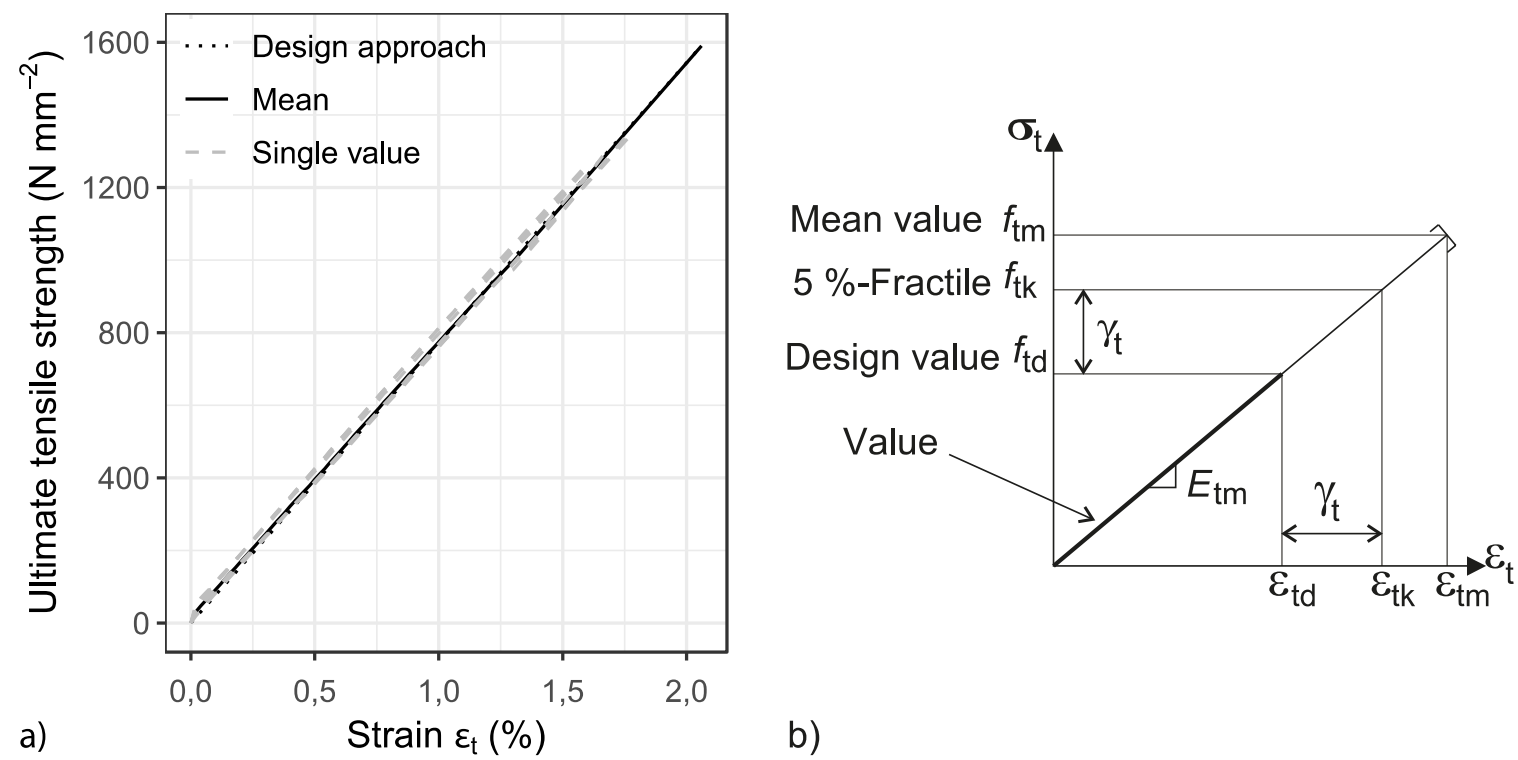

b)

Fig. 3 Stress-strain diagrams [15] (a) AR-Glass reinforcement. (b) Design of textilereinforced components

By using the results of the standardised tensile test, the material behaviour of the fibre strands with a linear-elastic approach can be determined with Equations 2 and 3. In principle, only two of the following parameters are required for the characterisation of the textile reinforcement behaviour since they have a relationship between them:

- $E_{\mathrm{tm}}$ : mean value of the modulus of elasticity (or Young's modulus)

- $f_{\mathrm{t}, \mathrm{u}}$ : ultimate tensile strength

- $\varepsilon_{\mathrm{t}, \mathrm{u}}:$ ultimate strain

By assuming such linear-elastic behaviour, as it is illustrated in Figure $3 b$, the textile stress value of each strain (Equation 2) and the strain value of each stress (Equation 3) can be determined for each point of the stress-strain diagram by using the mean value of the modulus of elasticity.

$$
\begin{gathered}
\sigma_{\mathrm{t}}=\varepsilon_{\mathrm{t}} \cdot E_{\mathrm{tm}} \leq f_{\mathrm{t}, \mathrm{u}} \\
\varepsilon_{\mathrm{t}}=\frac{\sigma_{\mathrm{t}}}{E_{\mathrm{tm}}} \leq \varepsilon_{\mathrm{t}, \mathrm{u}}
\end{gathered}
$$


The measurement of the strain can be stopped at around $60 \%$ of the failure load to preserve the LVDTs from damage. This procedure is possible since the tests clearly show that the textile reinforcement behaves in a linear-elastic manner until it breaks, and therefore, the modulus of elasticity is practically constant.

\subsubsection{Material parameters for the design approach}

The material parameters are usually described through distribution functions, which are characterised by statistical parameters (or moments). The robustness of a distribution function strongly depends on the extent of representative data or, in this case, measurements. For this reason, several hundred standardised tensile tests were conducted. Since it has been assumed that ultimate tensile strengths are normally distributed without further appraisals [24], the test results were used to evaluate the normality assumption.

The measured ultimate tensile strengths were divided into classes and then compiled in a histogram. The results of the AR-glass textiles are shown in Figure 4a. A close observation of this figure leads to an immediate exclusion of some distribution families. The values were then converted into a frequency density $h(\mathrm{x})$ by generating the ratio of the relative frequency to the class width. If points are now placed in the mean values of the classes and these are connected, a curve of the frequency density is obtained, as it is illustrated in Figure 4b. The shape of this curve provides a rough indication of the most suitable distribution family. In this case, the curve plotted in Figure $4 \mathrm{~b}$ resembles the probability density function of a Normal distribution. The expected value was approximated by the arithmetic mean value $\mu_{\mathrm{X}} \approx \bar{x}_{\mathrm{X}}=1590 \mathrm{~N} \mathrm{~mm}^{-2}$ and the standard deviation was estimated by the empirical standard deviation $\sigma_{\mathrm{X}} \approx s_{\mathrm{X}}=138 \mathrm{~N} \mathrm{~mm}^{-2}$. The mean value $\bar{x}_{\mathrm{X}}$ and the empirical standard deviation $s_{\mathrm{X}}$ were calculated from more than 400 experiments and then used in Equation 4, which represents the probability density function of a Normal distribution [25].

$$
f(x)=\frac{1}{\sigma_{\mathrm{X}} \sqrt{2 \pi}} \exp \left(-\frac{\left(x-\mu_{\mathrm{X}}\right)^{2}}{2 \sigma_{\mathrm{X}}^{2}}\right)=\frac{1}{138 \sqrt{2 \pi}} \exp \left(-\frac{(\mathrm{x}-1590)^{2}}{2(138)^{2}}\right)
$$




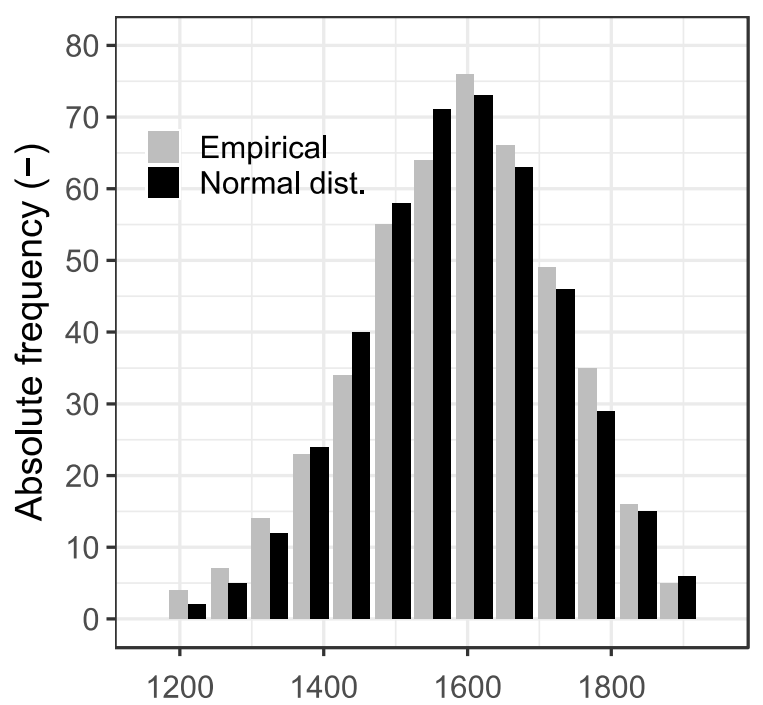

a) Ultimate tensile strength $\left(\mathrm{N} \mathrm{mm}^{-2}\right)$

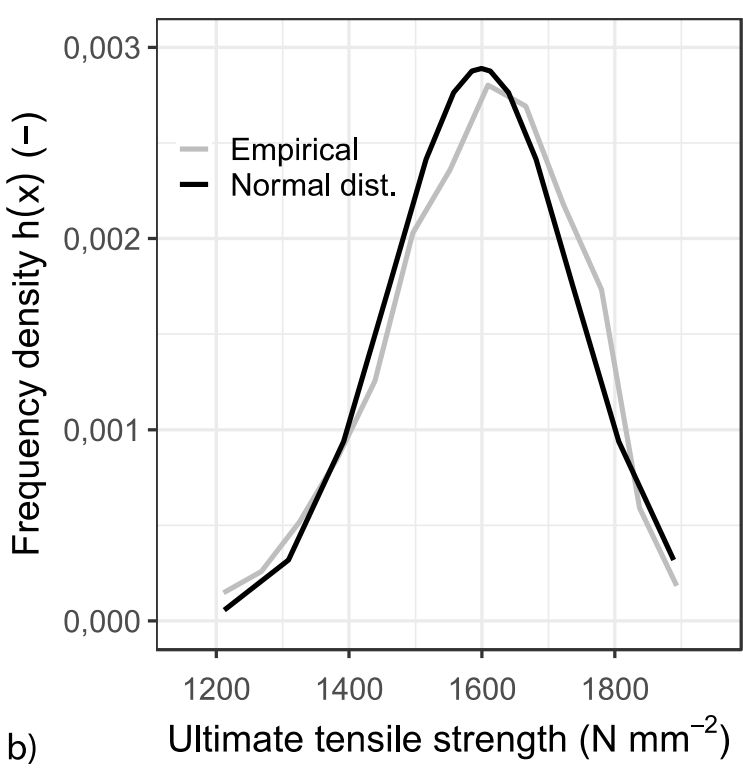

b)

Fig. 4 Statistical evaluation of the ultimate tensile strength [15] (a) Histogram for the AR-Glass reinforcement (empirical and theoretical values). (b) Probability density function of the AR- Glass reinforcement

It is important to highlight that the graphical plot alone does not confirm the assumption that the ultimate tensile strength is normally distributed. Therefore, a Chi-Square $\left(\chi^{2}\right)$ test was performed to test the data normality. This test starts with the definition of two hypotheses: $H_{0}$ and $H_{1}$. While the so-called null hypothesis $H_{0}$ states that the ultimate tensile strength is normally distributed, $H_{1}$ expresses the opposite [26]. In this test, the expected outcome frequencies and the observed outcome frequencies are compared (Figure 4a). If the difference $\chi^{2}$ between the functional value is greater than the critical value $\chi_{(1-\alpha) ; v}^{2}$, the null hypothesis is rejected. This critical value was calculated for a significance level of $\alpha=5 \%$, which corresponds to the $(1-\alpha)=95 \%$ fractile of the $\chi^{2}$ distribution with the associated degree of freedom $v=12$. In the $\chi^{2}$ test, the difference obtained is $\chi^{2}=9$, which is below the critical value $\chi_{(1-0.05) ; 12}^{2}=21$.

The tests conducted do not reject that the ultimate tensile strengths of the fibre strand soaked with epoxy resin can be described by a Normal distribution function with satisfactory accuracy. This has been observed in various textile variants for both directions: warp and weft. Based on these conclusions, the arithmetic mean value, and the empirical standard deviation (i.e., the most common statistical estimators) were used to approximate the same statistical parameters of a Normal distribution. This describes the random character of the ultimate tensile strength. The entire set of test results cannot be presented in this paper due to space limitations; however, the results are available in [17] for consultation. 


\subsection{Influence of the length of the fibre strand}

\subsubsection{Experimental investigations}

The influence of the length of the fibre strand on the ultimate tensile strength was investigated for the four lengths of the AR-glass textile (see section 2.2) placed in the weft direction. Each length was tested at least seven times. The results were statistically evaluated under the assumption of a Normal distribution. These are summarised in Figure 5, where the influence of the length on the ultimate tensile strength can be clearly observed. The mean value decreases non-linearly with an increasing length of the fibre strands. The fibre strand with a length of $60 \mathrm{~mm}$ - the shortest length - registered an average ultimate tensile strength of $1709 \mathrm{~N} \mathrm{~mm}^{-2}$. On the other extreme, the tensile strength of a fibre strand with a length of $640 \mathrm{~mm}$ registered an average ultimate tensile strength of $1257 \mathrm{~N} \mathrm{~mm}^{-2}$.

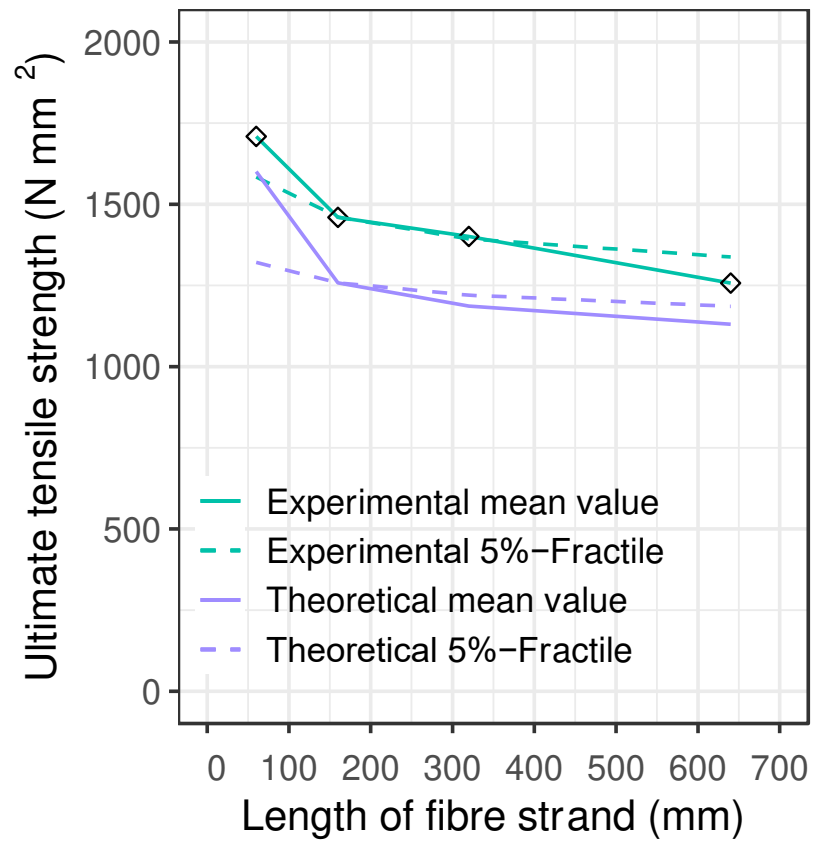

Fig. 5 Ultimate tensile strength of the textiles depending on the length of the fibre strands

The authors believe that such difference can be justified by the scale effect, in which the number of imperfections increases with a growing length of the fibre strand. Rypl [27] and Chudoba [28] also observed a similar trend. These researchers found that the standard deviation decreases with an increasing length of fibre strands. 

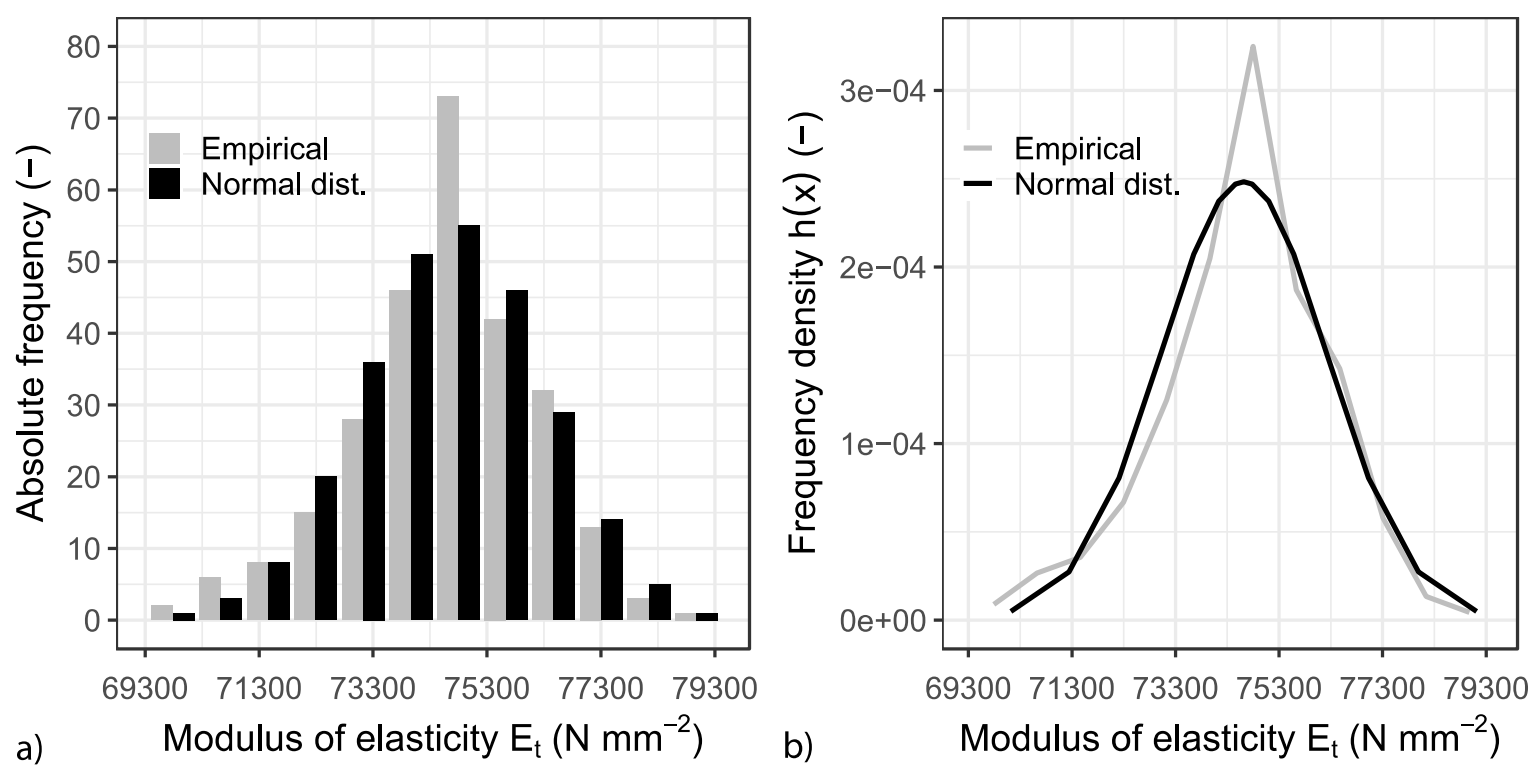

Fig. 6 Statistical evaluation of the modulus of elasticity (a) Histogram for the AR-Glass reinforcement (observed values and expected values). (b) Probability density function of the AR- Glass reinforcement

The influence of the fibre strand length on the modulus of elasticity was investigated for the four lengths of the AR-glass textile (see section 2.2) placed in the weft direction. Each length was tested at least seven times. The results were statistically evaluated under the assumption of a Normal distribution. These are summarised in Figure 6. Figure 6a shows the histograms for AR glass textile with the absolute frequencies. The grey bars represent the measured empirical values, the black bars represent the expected absolute frequencies. The frequency density curve obtained is illustrated in Figure $6 \mathrm{~b}$, resembling a probability density function of a Normal distribution. In this curve, the expected value was approximated by the arithmetic mean value $\mu_{\mathrm{X}} \approx \bar{x}_{\mathrm{X}}=74618 \mathrm{~N} \mathrm{~mm}^{-2}$ and the standard deviation was estimated by the empirical standard deviation $\sigma_{\mathrm{X}} \approx s_{\mathrm{X}}=1610 \mathrm{~N} \mathrm{~mm}^{-2}$. The mean value $\bar{x}_{\mathrm{X}}$ and the empirical standard deviation $s_{\mathrm{X}}$ were calculated using Equation 5, which represents the probability density function of a Normal distribution [25], as previously mentioned.

$$
f(x)=\frac{1}{\sigma_{\mathrm{X}} \sqrt{2 \pi}} \exp \left(-\frac{\left(x-\mu_{\mathrm{X}}\right)^{2}}{2 \sigma_{\mathrm{X}}^{2}}\right)=\frac{1}{1610 \sqrt{2 \pi}} \exp \left(-\frac{(x-74618)^{2}}{2(1610)^{2}}\right)
$$

The normality assumption was also evaluated with a Chi-Square test $\left(\chi^{2}\right)$, where the expected outcome frequencies and the observed outcome frequencies are compared. The test indicated that for a significance level of $\alpha=5 \%$, the existing values $\chi^{2}$ are always below 
the permissible critical value $\chi_{(1-0.05) ; 12}^{2}$. The entire set of test results cannot be not presented in this paper due to space limitations; however, the results are available in [17] for consultation. The results confirm that the modulus of elasticity of fibre strands soaked with epoxy resin can be described by a Normal distribution function with satisfactory accuracy. Thus, similarly to the previous analysis, the arithmetic mean value and empirical standard deviation/variance were used to determine the statistical parameters of the Normal distribution (i.e., the expected value and the standard deviation/variance).

\subsubsection{Theoretical investigations}

The statistical background must be known for the conception of a design model and for the calculations needed in a reliability analysis. If this background is known only empirically, multiple tensile tests are needed for each fibre strand length. However, the authors believe that to derive conclusions for each length, only the results of the standardised tensile test are needed. To this end, the theoretical investigations in this section can be used to determine the values required by means of mathematical calculations.

In this theoretical assessment, the fibre strands with a length of $160 \mathrm{~mm}$ can be used to approximate the respective statistical parameters. These elements were successively connected in series and the ultimate tensile strength of each element was characterised by a normally distributed random variable $X$. By using the extreme value theory, it is possible to determine not only the expected value and the standard deviation of the ultimate tensile strength of a single fibre strand with a length of $160 \mathrm{~mm}$, but also the distribution function of multiple fibre strands connected in series. The fibre strands connected in series can be compared to a chain where if one element fails, a total failure of the system will occur. In this case, it was assumed that the weakest link governs the failure. Thus, the minimum ultimate tensile strength that governs the series system, the so-called minimum $M_{\mathrm{n}}$, can be determined through an extreme value theory. For any number of fibre strands $n$, the distribution function of the minimum $F_{M_{n}}(\mathrm{x})$ can be calculated through Equation 6 [26]. To this end, it is used the cumulative distribution function $F_{\mathrm{X}}(\mathrm{x})$ of the ultimate tensile strength, which can be derived from the results of the standardised tensile tests on a fibre strand with a length of $160 \mathrm{~mm}$.

$$
\mathrm{P}\left(M_{\mathrm{n}} \leq \mathrm{x}\right)=F_{M_{\mathrm{n}}}(\mathrm{x})=1-\left[1-F_{\mathrm{X}}(\mathrm{x})\right]^{n}
$$

Equation 6 is only valid for independent and identically distributed random variables with a cumulative distribution function $F_{\mathrm{X}}(\mathrm{x})$ [26]. This is the case of fibre strands connected 
successively one behind the other since each link is assumed to have the same distribution function. By derivating Equation 6, the probability density function $f_{M_{\mathrm{n}}}(\mathrm{x})$ of the minimum ultimate tensile strength $M_{\mathrm{n}}$ can be determined through Equation 7:

$$
f_{M_{\mathrm{n}}}(\mathrm{x})=f_{\mathrm{X}}(\mathrm{x}) \cdot n \cdot\left[1-F_{\mathrm{X}}(\mathrm{x})\right]^{n-1}
$$

The fractile values of the extreme value distribution can be calculated by rearranging Equation 6:

$$
\begin{gathered}
F_{M_{\mathrm{n}}}\left(x_{\mathrm{p}}\right)=1-\left[1-F_{\mathrm{X}}\left(x_{\mathrm{p}}\right)\right]^{n}=p \\
F_{X}\left(x_{\mathrm{p}}\right)=1-\sqrt[n]{1-p}
\end{gathered}
$$

If the tensile strength of each link is assumed normally distributed, the fractile values of the extreme value distribution can be calculated according to Equation 10:

$$
x_{\mathrm{p}}=F_{\mathrm{X}}^{-1}\left(x_{\mathrm{p}}\right)=\mu_{\mathrm{X}}+\sigma_{\mathrm{X}} \Phi^{-1}(1-\sqrt[n]{1-p})
$$

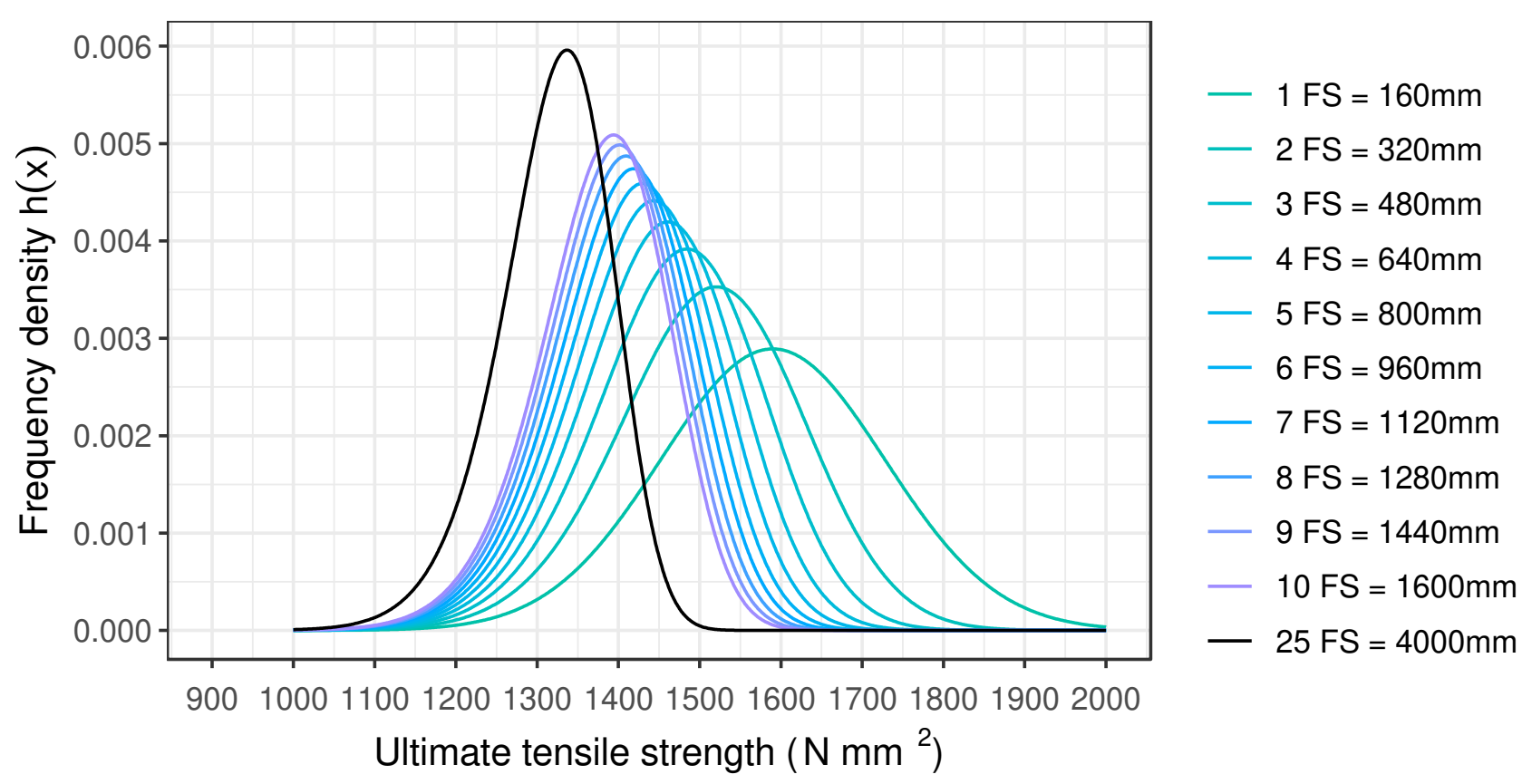

Fig. 7 Probability density function of the ultimate tensile strength for a different number of fibre strands (FS) (adapted from [15])

The densities of the extreme value distributions of different fibre strand lengths were calculated with Equation 7 and compared in Figure 7. This figure shows that as the fibre strand length increases, the expected value, and the standard deviation of the extreme value 
distribution decrease. This trend is illustrated by the increasing slenderness of the curves and the shift to the left. The density of the extreme value distribution for the ultimate tensile strengths of $n=25$ fibre strands connected in series is also visible in the black line of Figure 7. This density is neither symmetrical nor normally distributed. For the convergence of the distribution, it was assumed that a generalised extreme value distribution type-I (Gumbel distribution) might be used. A Gumbel distribution has the advantage to facilitate the calculations in reliability assessments. This distribution is characterised by two parameters: $a$ and $u$. The probability density function of this distribution for data minimum is described as follows:

$$
f(x)=a \cdot e^{a \cdot(x-u)-e^{a \cdot(x-u)}}
$$

To approximate the extreme value distribution by a Gumbel distribution according to Equation 7, the ultimate tensile strengths of the 50\%-Fractile (median) and the 5\%-Fractile of the extreme value distribution are determined. Then, these values are assumed for the $50 \%$ Fractile and the 5\%-Fractile of the Gumbel distribution, respectively. The parameters $a$ and $u$ of the Gumbel distribution can then be determined according to Equations 12 and 13.

$$
\begin{gathered}
a=\frac{2.60368}{F_{M_{n}}^{-1}(0.05)-F_{M_{n}}^{-1}(0.50)} \\
u=1.14077 \cdot F_{M_{n}}^{-1}(0.50)-0.14077 \cdot F_{M_{n}}^{-1}(0.05)
\end{gathered}
$$

with $F_{M_{n}}^{-1}(0.50)$ corresponding to the 50\%-Fractile, $F_{M_{n}}^{-1}(0.05)$ being the $5 \%$-Fractile of the extreme value distribution according to Equation 6, and $n$ being the number of fibre strands.

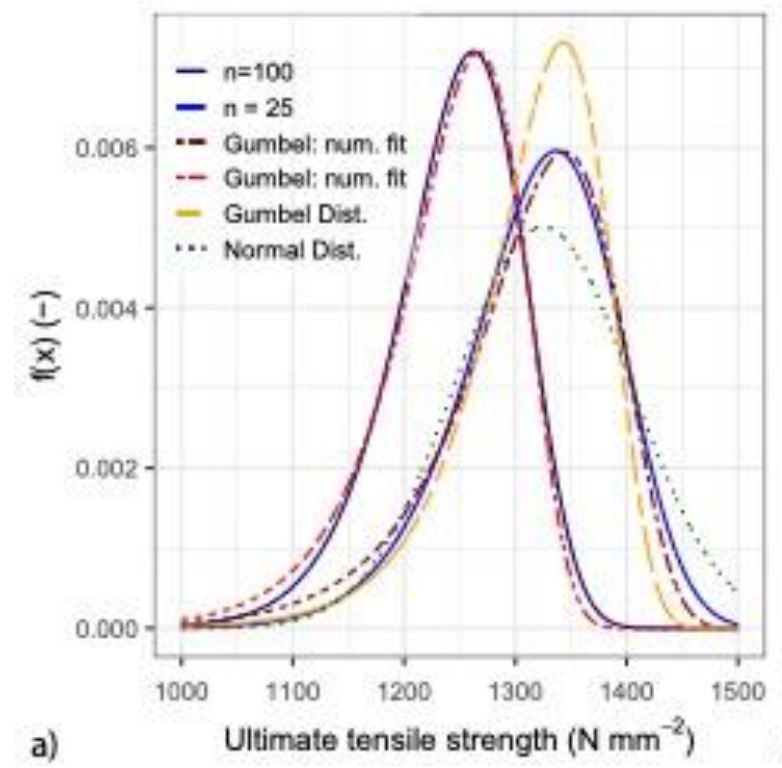

a)

b)

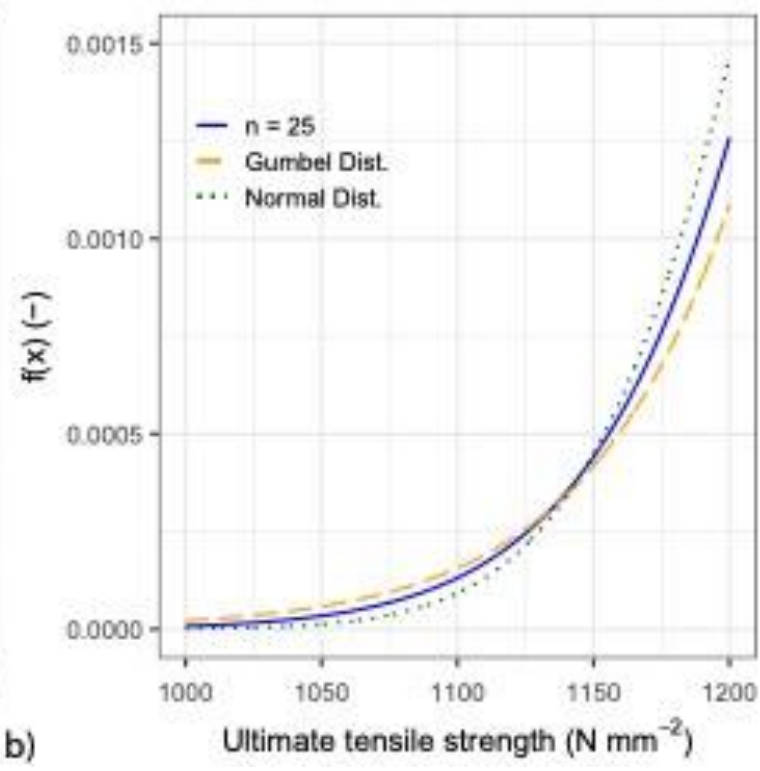


Fig. 8 Probability-Density-Function of the extreme-value function and the approximation through a Normal and a Gumbel distribution functions (a) entire distribution and (b) selected area of the distribution at the tails

Table 1 Extreme value distribution approximated by a Normal distribution and a Gumbel distribution for selected fractile values and for $n=25$ fibre strands

\begin{tabular}{|c|c|c|c|c|}
\hline Fractile & $\begin{array}{c}\text { Fractile } \\
\text { Value } \\
\text { (Eq. 9) }\end{array}$ & $\begin{array}{c}\text { Extreme value } \\
\text { distribution } \\
\text { (Eq. 7) }\end{array}$ & $\begin{array}{c}\text { Normal } \\
\text { distribution } \\
\text { (Eq. 10) }\end{array}$ & $\begin{array}{c}\text { Gumbel } \\
\text { distribution } \\
\text { (Eq. 11) }\end{array}$ \\
\hline $5 \%$ & 1193.882 & 0.001117997 & 0.001295237 & 0.0009686911 \\
\hline $2 \%$ & 1154.875 & 0.000491684 & 0.0005132108 & 0.0004586016 \\
\hline $1 \%$ & 1127.498 & 0.0002604478 & 0.0002322123 & 0.0002687753 \\
\hline $0.1 \%$ & 1045.689 & $3.022114 \mathrm{e}-05$ & $1.07336 \mathrm{e}-05$ & $5.344032 \mathrm{e}-05$ \\
\hline $0.01 \%$ & 973.806 & $3.384514 \mathrm{e}-06$ & $3.014754 \mathrm{e}-07$ & $1.282811 \mathrm{e}-05$ \\
\hline
\end{tabular}

Figure 8 shows the probability density functions of the extreme value function for two different numbers of fibre strands $n: n=25$ and $n=100$. For each $n$, the probability density function is approximated by a Normal distribution and by a Gumbel distribution. In Figure $8 \mathrm{a}$ it can be observed that an approximation by a Gumbel distribution is more suitable with an increasing number of $n$ (see curve for $n=100$ ). An approximation by a Normal distribution lies slightly below the curve of the extreme value distribution.

Particularly relevant for the evaluation of failure probabilities is the behaviour of the Gumbel and the Normal distribution at the tails of the functions (Figure 8b). Table 1 shows that for fractile values smaller than $2 \%$, the Gumbel distribution lies slightly above the extreme value distribution, whereas the Normal distribution presents lower values. This trend can be seen in Figure 8b, where the Normal distribution curve moves its course to below the extreme distribution curve at an ultimate tensile strength of roughly below $1150 \mathrm{~N} \mathrm{~mm}^{-2}$. Such tail behaviour is not particularly surprising since, in theory, Normal distributions are characterised by thinner tails than those from extreme value distributions. Based on the values assessed, it can be stated that an approximation through a Normal distribution leads to underestimated values of failure probabilities, which in reliability analyses can be problematic. For very low failure probabilities, a Gumbel distribution is on the safe side.

For design purposes, the 5\%-Fractile is a governing value [29-30], as it is also used as the characteristic tensile strength of the textile reinforcement $f_{\mathrm{t}, \mathrm{k}}$. The design value of the tensile strength $f_{\mathrm{t}, \mathrm{d}}$ is determined by dividing the characteristic value $f_{\mathrm{t}, \mathrm{k}}$ by the partial safety factor $\gamma_{\mathrm{t}}$ (Equation 14). With a partial safety factor $\gamma_{\mathrm{t}}=1.0$, the characteristic value would be the same as the design value. 


$$
f_{\mathrm{t}, \mathrm{d}}=\frac{f_{\mathrm{t}, \mathrm{k}}}{\gamma_{\mathrm{t}}}
$$

\subsection{Influence of the number of fibre strands}

\subsubsection{Experimental investigations}

The influence of the number of fibre strands on the ultimate tensile strength was investigated with uniaxial tensile tests on composite members. In total, eight series with five tests (beginning with one fibre strand and ending with eight) were performed. In addition, a standardised tensile test was carried out to show that the testing setup and procedures do not influence the investigation. The results are illustrated in the stress-strain diagrams of Figure 9. In the tensile tests of the composite members, a textile failure always occurs. The textile tension $\sigma_{\mathrm{t}}$ was calculated with Equation 1 by considering the measured force $F$ and the accumulated filament cross sectional area $A_{\text {r. }}$ Figure 9 displays an example of the stress-strain curve of an AR-glass textile. While in Figure 9a the test sample was reinforced with only two fibre strands, in Figure $9 \mathrm{~b}$ eight fibre strands were installed. The black curve represents the mean course of the individual experiments. The curves of the individual experiments are shown in grey. Figure 9 also shows that during the experiment three states occur. In state IIb, the curve does not flatten, but runs parallel to the results of the standardised tensile test on the plain fibre strand, which is illustrated as dashed lines. In both tests, the same modulus of elasticity for the textile is achieved in state IIb. This supports the assumption that the test setup can be used to determine the influence of the number of fibre strands. Simultaneously, it can be concluded that the modulus of elasticity is not influenced by the number of fibre strands.

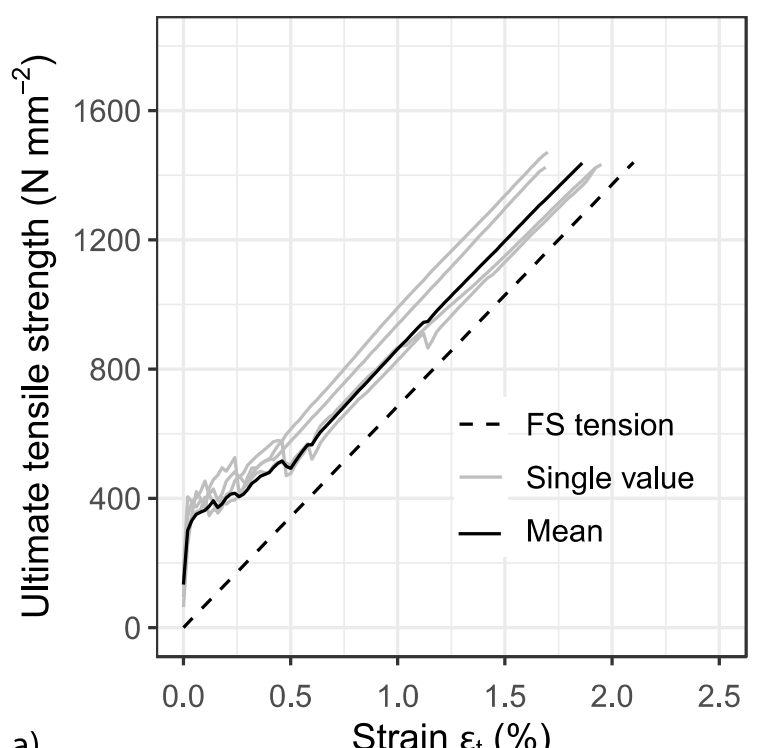

a)

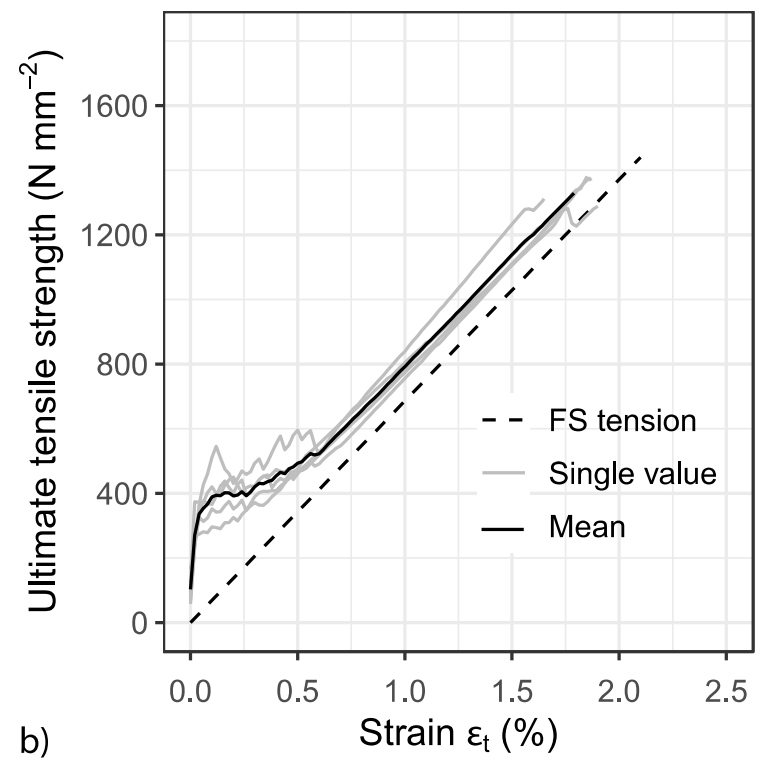


Fig. 9 Tension-Strain diagram [15]: a) two and b) eight embedded fibre strands

\subsubsection{Theoretical investigations}

The experimental investigations show that the number of fibre strands does not influence the mean value of the modulus of elasticity. This finding cannot be transferred to the ultimate tensile strength, since for each number of fibre strands, the tensile strength follows a distribution function with different parameters. Like in the analysis in Section 3.2.2, only the results of the standardised tensile test on an individual fibre strand are required to derive a possible mathematical relationship for any number of fibre strands. For this purpose, it is considered that the fibre strands with a length of $160 \mathrm{~mm}$ are virtually and successively connected next to one another. To each element, it is considered a Normal distribution, which was determined with the standardised tensile test for a single strand with a length of $160 \mathrm{~mm}$ (see section 3.1.2).

The fibre strands connected next to one another can be compared to a parallel connection, where in principle if one element fails, a total failure occurs providing that no redistribution of stresses occurs. In contrast to steel that is characterised by a ductile failure behaviour, a brittle failure occurs as soon as the end of the linear-elastic range is reached. During the test, each fibre strand in the parallel system is loaded with the same load; however, the strand does not have the same ultimate tensile strength due to the material scatter. As soon as the ultimate tensile strength of the weakest element is reached, it suddenly fails, and the force has to be absorbed by the remaining elements. Nevertheless, a redistribution can only take place if the remaining fibre strands have sufficient residual load-bearing capacity, which is only possible with a high number of fibre strands, or a very large spread of the ultimate tensile strength. Considering a system of $n$ identical fibre strands, which ultimate tensile strengths $X_{\mathrm{i}}$ following a cumulative distribution function $F_{X}(\mathrm{x})$, the ultimate tensile strength $R$ of the system can be described as:

$$
R=\max \left(n \hat{X}_{1},(n-1) \hat{X}_{1}, \ldots, \hat{X}_{n}\right)
$$

with $\hat{X}_{1}, \ldots, \hat{X}_{n}$ being the ultimate tensile strength of the individual strand sorted in ascending order by size. As a safe side approximation, it can be assumed that the weakest link governs the failure mechanism. Thus, a parallel connection can be compared to the behaviour of a series connection due to the nearly ideal brittle behaviour of the component. Consequently, the calculation of the cumulative distribution function of the minima $F_{M_{n}}(\mathrm{x})$ can be approximately calculated with Equation 6. 


\subsubsection{Comparison of the experimental and theoretical investigations}

Based on the above-described considerations, the experimental and theoretical investigations were compared and evaluated. To this end, a chain system of fibre strands was considered under the assumption that redistribution of stresses cannot occurs when the weakest fibre strand fails, as described above. Then, the theoretical mean value of the ultimate tensile strength as well as the characteristic value the ultimate tensile strengths $(5 \%$ Fractile) were assessed by considering the generalised extreme value distribution type I (Gumbel distribution). Then, these values were compared to the results determined through simulations. In this evaluation, it was assumed that each fibre strand of a chain is normally distributed. The values described in Section 3.1.2 were used to characterise the ultimate tensile strength, where the mean ultimate tensile strength is $\mu_{\mathrm{X}} \approx \bar{x}_{\mathrm{X}}=1590 \mathrm{~N} \mathrm{~mm}^{-2}$ and the standard deviation is $\sigma_{\mathrm{X}} \approx s_{\mathrm{X}}=138 \mathrm{~N} \mathrm{~mm}^{-2}$. By using the principles of a direct Monte-Carlo simulation, 50000 simulations were performed in the statistical software $R$ [31]. Furthermore, a theoretical calculation was also performed by assessing the expected value through Equation 7. The results are illustrated in Figure 10 and summarised in Table 2.

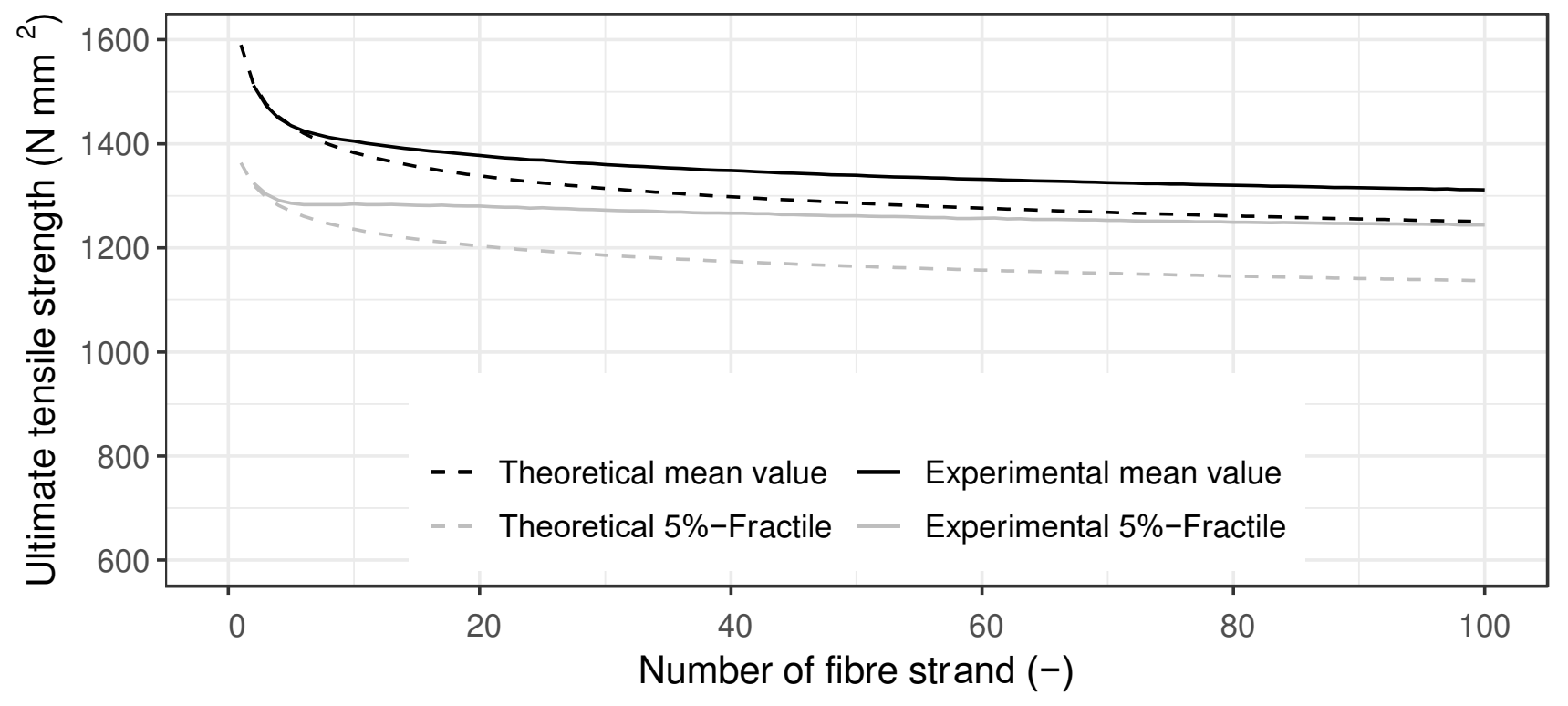

Fig. 10 Ultimate tensile strength depending on the number of fibre strands

Table 2 Ultimate tensile strength: Comparison of the simulations and the theoretical investigations

\begin{tabular}{|l|l|l|}
\hline & Expected value $\left(\mathrm{N} \mathrm{mm}^{-2}\right)$ & $5 \%$-Fractile value $\left(\mathrm{N} \mathrm{mm}^{-2}\right)$ \\
\hline
\end{tabular}




\begin{tabular}{|c|c|c|c|c|c|c|}
\hline \multirow{2}{*}{$\begin{array}{c}\text { No. fibre } \\
\text { strands }\end{array}$} & \multicolumn{3}{|c|}{ (i.e., mean value) } & \multicolumn{3}{c|}{} \\
\cline { 2 - 7 } & Simulation & $\begin{array}{c}\text { Gumbel } \\
\text { distribution }\end{array}$ & $\begin{array}{c}\text { Difference } \\
(\%)\end{array}$ & Simulation & $\begin{array}{c}\text { Gumbel } \\
\text { distribution }\end{array}$ & $\begin{array}{c}\text { Difference } \\
(\%)\end{array}$ \\
\hline 5 & 1435 & 1434 & $-0.07 \%$ & 1281 & 1270 & $-0.87 \%$ \\
\hline 10 & 1404 & 1383 & $-1.55 \%$ & 1282 & 1236 & $-3.71 \%$ \\
\hline 25 & 1367 & 1325 & $-3.21 \%$ & 1272 & 1194 & $-6.57 \%$ \\
\hline 50 & 1339 & 1286 & $-4.13 \%$ & 1258 & 1165 & $-7.96 \%$ \\
\hline 75 & 1323 & 1265 & $-4.55 \%$ & 1247 & 1148 & $-8.63 \%$ \\
\hline 100 & 1311 & 1250 & $-4.90 \%$ & 1241 & 1137 & $-9.10 \%$ \\
\hline
\end{tabular}

The results of the simulation confirm that the mean ultimate tensile strength decreases as the number of fibre strands increases, where the curves tend to flatten. Consequently, the standard deviation and the coefficient of variation also decrease with an increasing number of fibre strands. For an increasing number of fibre strands, the extreme value distribution approximated by a Gumbel distribution loses expression (i.e., decreases at a very slow pace). The results also show that the differences between the simulated values and the mathematical approximation through a Gumbel distribution can go up to around 9\%, which can be explained by the fact that a Gumbel distribution does not consider a redistribution of stresses after the failure of the first fibre strand. These results confirm that a Gumbel approximation is on the safe side.

\subsection{Summary of the tests}

The above-described results demonstrate that the standardised tensile test performed for a single fibre strand with a length of $160 \mathrm{~mm}$ is considered sufficient to determine all the statistical parameters needed for the design model of a textile reinforcement - and ultimately, for further reliability assessments. This means that a designer would not need to consider the original distribution of the random variable $X$, but instead, would simply need to adopt suitable statistical parameters that are representative of the ultimate tensile strengths and modulus of elasticity. In this context, the results seem to support the assumption that ultimate tensile strength can be characterised by a Gumbel distribution. This fitting must be done for a reasonable number of fibre strands and for a specific expected value $\mu_{\mathrm{X}}$ and specific standard deviation $\sigma_{\mathrm{X}}$. It is relevant to mention that such number of fibre strands is complex to define with precision. However, the authors believe that assuming at least 50 fibre strands is a safe assumption since it is not conceivable that the redistribution of stresses takes place beyond such number. In fact, for larger numbers the fibre strands will be distant from each other to allow for a redistribution. In its turn, the modulus of elasticity can be described by a Normal distribution. 
The designed value of the tensile strength $f_{\mathrm{td}}$ is the basis for the structural calculations with bending and shear load, which are described in [22, 32-28]. As it has been discussed in this paper, the ultimate tensile strength depends on the length and number of fibre strands, which means that the material parameters determined for individual fibre strands cannot be directly transferred to the behaviour of a component. Since the strain length will be greater than $160 \mathrm{~mm}$ and the number of fibre strands will be more than one, a conversion must take place. Such conversion raises the question of which number or length of fibre strand is the most reasonable to represent a realistic reinforced concrete element. A possible answer could be the 5\%-Fractile values since these so-called characteristic tensile strength of the reinforcement $f_{\mathrm{tk}}$ form the basis for the design values of the tensile strength $f_{\mathrm{td}}$ (Equation 14 and Figure $3 b$ ). Considering that the 5\%-Fractile needs to be used for the design, the problem is not as pronounced, as it can be seen in Figure 11, where the absolute differences of the textile stresses of the 5\%-Fractile for the different lengths and numbers of fibre strands are illustrated. The difference is generated from the 5\%-Fractile values of the ultimate tensile strength of $n$ and $(n-1)$ fibre strands.

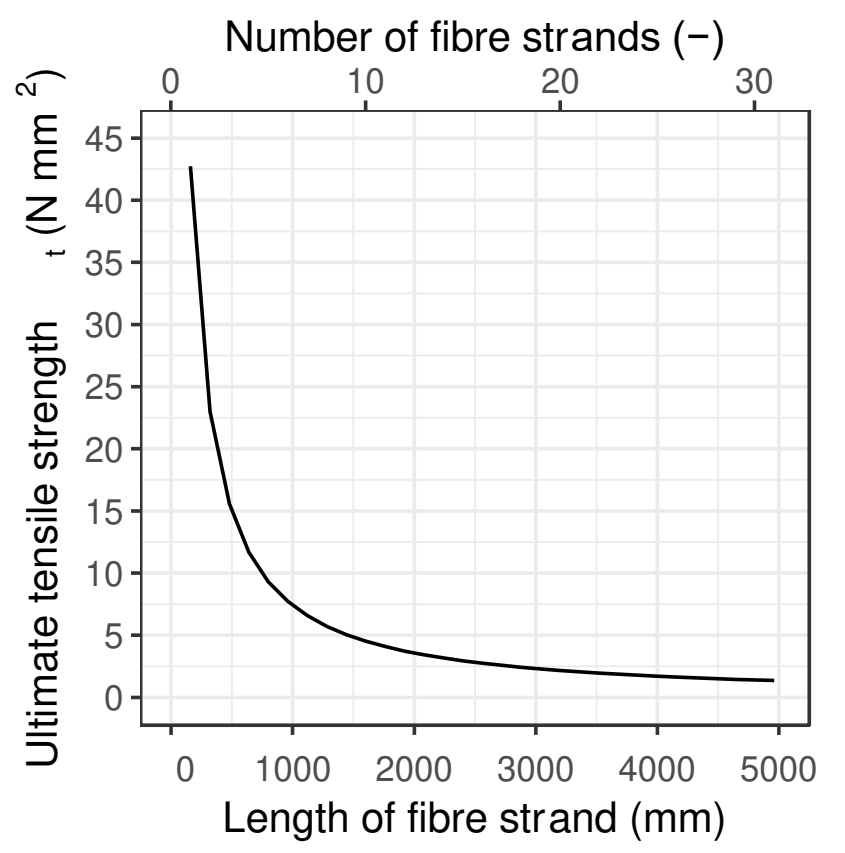

Fig. 11 Margin of the $5 \%$-Fractile values of $n$ and (n-1)-fibre strands [15]

Figure 11 also indicates that for a small number of fibre strands, the 5\%-Fractile of the tensile strength is strongly affected by the number of fibre strands. Whereas, from around five strands, the curve flattens out sharply and the difference between the characteristic values becomes gradually smaller. From a length of $1600 \mathrm{~mm}$, which corresponds to ten strands, the gradient is almost constant. This means that the $5 \%$-Fractile value is only slightly higher 
for ten fibre strands than for eleven. In the case of the AR-glass examined, the value is 4.5 N.mm ${ }^{-2}$, which corresponds to just $2.8 \%$ of the mean ultimate tensile strength. Therefore, it is recommended, to use a reasonable number of fibre strands for the determination of the characteristic value, which is in the area, where the curve slope of the 5\%-Fractile differences becomes almost constant.

As explained before, the standardised tensile test on an individual fibre strand needs to be carried out, and then, the ultimate tensile strength must be adjusted by using the extreme value theory through Equations 6 and 7. With this approximation, the mean value $f_{\mathrm{tm}}$, the characteristic value $f_{\mathrm{tk}}$, and finally, the design value $f_{\mathrm{td}}$ can be determined.

The design strain $\varepsilon_{\mathrm{td}}$ is also required for the design model. To this, it is sufficient to measure the textile tension and divide it by the modulus of elasticity (Equation 3 ). The tests showed that the modulus of elasticity is not influenced by the number of fibre strands. The mean value from the standardised test on a single fibre strand can be used as an appropriate modulus of elasticity.

\section{Conclusion}

The results show that the standardised tensile test is sufficient to determine all the statistical data and material parameters necessary for the structural design of concrete components with textile reinforcement impregnated with epoxy resin. To this end, only the measurements of the ultimate tensile strength and the modulus of elasticity of a fibre strand, cut out of the textile grid are needed.

The tests show that a fibre strand, when subjected to tensile stress, has a linear-elastic behaviour until it fails. The results also indicate that the ultimate tensile strength depends on both the length and number of fibre strands. With an increasing length and number of fibre strands, the expected value and the scatter of the ultimate tensile strength decrease nonlinearly. As soon as a certain length and number is exceeded, the characteristic ultimate tensile strength is hardly influenced. With the help of extreme value theory, the statistical values can be calculated for any length and number of strands. To simplify the calculation, the extreme value distribution can be approximated by a Gumbel distribution. The approximation by a Normal distribution is not recommended. The main advantage of the described approach is that only the results of the standardised tensile test on an individual fibre strand are needed. Afterwards, a reliability assessment calculation can be carried out to derive an appropriate partial safety factor for design purposes (e.g., [21, 30]). 
Among the future challenges, the most prevailing is the improvement of the current theoretical model adopted in this study. The extreme value distribution was selected to describe the weakest ultimate tensile strength; however, the mathematical model adopted does not consider the possibility to redistribute the load. A more robust mathematical model shall be considered in future work. Focus shall also be placed on investigating a possible correlation between the modulus of elasticity and the ultimate tensile strength.

\section{References}

1. Kromoser B, Preinstorfer P, Kollegger J (2019) Building lightweight structures with carbon-fibre-reinforced polymer-reinforced ultra-high-performance concrete: Research approach, construction materials, and conceptual design of three building components. Structural Concrete 20:730-744. doi: 10.1002/suco.201700225

2. Schumann A, Michler H, Schladitz F, Curbach M (2018) Parking slabs made of carbon reinforced concrete. Structural Concrete 19:647-655. doi: $10.1002 /$ suco. 201700147

3. Scholzen A, Chudoba R, Hegger J (2015) Thin-walled shell structures made of textile-reinforced concrete: part I: structural design and construction. Structural Concrete 16:106-114. doi: 10.1002/suco.201400046

4. Rempel S, Will N, Hegger J, Beul J (2015) Filigrane Bauwerke aus Textilbeton: Leistungsfähigkeit und Anwendungspotenzial des innovativen Verbundwerkstoffs. Beton-und Stahlbetonbau 110(S1):83-93. doi: 10.1002/best.201400111

5. Adam V, Bielak J, Dommes C, Will N, Hegger J (2020) Flexural and Shear Tests on Reinforced Concrete Bridge Deck Slab Segments with a Textile-Reinforced Concrete Strengthening Layer. Materials 13(18): 4210. doi: 10.3390/ma13184210

6. Bielak J, Schmidt M, Hegger J, Jesse F (2020) Structural Behavior of Large-Scale I-Beams with Combined Textile and CFRP Reinforcement. Applied Sciences 10(13):4265. doi: 10.3390/app10134625

7. Bielak J, Will N, Hegger J (2020) Zwei Praxisbeispiele zur Querkrafttragfähigkeit von Brückenplatten aus Textilbeton. Bautechnik 97: 20:499-507. doi: 10.1002/bate.202000037

8. Adam V, Bielak J, Will N, Hegger J (2020) Experimentelle Untersuchungen zur Verstärkung von Brückenfahrbahnplatten mit Textilbeton. BuSt 115. First Published online. doi: 10.1002/best.202000049 
9. Spelter A, Bergmann S, Bielak J, Hegger J (2019) Long-Term Durability of CarbonReinforced Concrete: An Overview and Experimental Investigations. Applied Sciences 9(8):1651. doi: 10.3390/app9081651

10. Spelter A, Rempel, S, Will N, Hegger J (2017) Prüfkonzept zur Untersuchung des Dauerstandverhaltens von textilbewehrtem Beton. Bauingenieur 92(9):364-369.

11. Spelter A, Rempel S, Will N, Hegger J (2018) Testing Concept for the Investigation of the Long-Term Durability of Textile Reinforced Concrete, In: Falikman, V; Realfonzo, R; Coppola, L; Hàjek, P; Riva, P. (Hrsg.): Durability and Sustainability of Concrete Structures (DSCS 2018): An ACI Technical Publication. American Concrete Institute. Farmington Hills, Michigan 55.1-55.9.

12. Wagner J, Spelter A, Hegger J, Curbach M (2020) Ermüdungsverhalten von Carbonbeton unter Zugschwellbelastung. Beton- und Stahlbeton 115(5):710-719. doi: 10.1002/best.201900104

13. Helbig T, Unterer K, Kulas C, Rempel S, Hegger J (2016) Fuß-und Radwegbrücke aus Carbonbeton in Albstadt-Ebingen: Die weltweit erste ausschließlich carbonfaserbewehrte Betonbrücke. Beton-und Stahlbetonbau 111:676-685. doi: $10.1002 /$ best.201600058

14. Alex R (2015) Fibre Reinforced Polymers (FRP) as Reinforcement for Concrete According to German Approvals. IOP Conference Series: Materials Science and Engineering 96:012013. doi: 10.1088/1757-899X/96/1/012013

15. Rempel S, Ricker M (2017) Ermittlung der Materialkennwerte der Bewehrung für die Bemessung von textilbewehrten Bauteilen. Bauingenieur 92: 280-288

16. Bielak J, Schmidt M, Hegger, J, Jesse F (2020) Structural Behavior of Large-Scale I-Beams with Combined Textile and CFRP Reinforcement. Applied Sciences 10: 4625. doi: 10.3390/app10134625

17. Rempel S (2018) Zur Zuverlässigkeit der Bemessung von biegebeanspruchten Betonbauteilen mit textiler Bewehrung. Doctoral dissertation, Ph. D. Thesis, RWTH Aachen University, Aachen, Germany

18. Rempel S, Kulas C (2015) Biegetragverhalten getränkter textiler Bewehrungselemente für Betonbauteile. Bauingenieur 90:248-251

19. Hinzen M (2017) Prüfmethode zur Ermittlung des Zugtragverhaltens von textiler Bewehrung für Beton. Bauingenieur 92:289-291.Hinzen M (2017) Prüfmethode zur Ermittlung des Zugtragverhaltens von textiler Bewehrung für Beton. Bauingenieur 92:289-291. 
20. Moceikis, R, Kičaitè, A, Skripkiūnas, G, \& Korjakins, A (2018) Ageing models and accelerated ageing tests of glass fiber reinforced concrete. Engineering Structures and Technologies 10(1):10-17.

21. Ricker M, Feiri T, Nille-Hauf K, Adam,V \& Hegger, J (2020) Enhanced reliability assessment of punching shear resistance models for flat slabs without shear reinforcement. Engineering Structures 226:111319. doi:

10.1016/j.engstruct.2020.111319

22. Rempel S, Ricker M, \& Hegger J (2020) Safety Concept for Textile-Reinforced Concrete Structures with Bending Load. Applied Sciences 10(20): 7328. doi: 10.3390/app10207328

23. Brameshuber W, Hinzen M, Dubey A, Peled A, Mobasher B, Bentur A, et al (2016) Recommendation of RILEM TC 232-TDT: test methods and design of textile reinforced concrete: Uniaxial tensile test: test method to determine the load bearing behavior of tensile specimens made of textile reinforced concrete. Materials and Structures/Materiaux et Constructions 49:4923-4927.

24. Kulas C (2013) Zum Tragverhalten getränkter textiler Bewehrungselemente für Betonbauteile. Doctoral dissertation, Ph. D. Thesis, RWTH Aachen University, Aachen, Germany

25. Plate EJ (1993) Statistik und angewandte Wahrscheinlichkeitslehre für Bauingenieure. Ernst \& Sohn Verlag. Bochum.

26. Meyna A, Pauli B (2010) Zuverlässigkeitstechnik. Quantitative Bewertungsverfahren. Hanser Verlag. RILEM.

27. Rypl R, Chudoba R, Mörschel U, Stapleton SE, Gries T, Sommer G (2015) A novel tensile test device for effective testing of high-modulus multi-Fibre strands. Journal of Industrial Textiles 44:934-947. doi: 10.1177/1528083714521069

28. Chudoba R, Vořechovský M, Eckers V, Gries T (2007) Effect of twist, fineness, loading rate and length on tensile behavior of multifibre strands (a multivariate study). Textile Research Journal 77:880-891. doi: 10.1177/0040517507081280

29. JCSS, (2001) Probabilistic model code. Joint Committee on Structural Safety. ISBN 978-3-909386-79-6. 2001

30. DIN EN 1990 (2010) Grundlagen der Tragwerksplanung; Deutsche Fassung EN 1990:2002. Beuth Verlag. Berlin.

31. R Core Team (2013) R: A language and environment for statistical computing. $R$ Foundation for Statistical Computing, Vienna, Austria. http://www.R-project.org/. 
32. Rempel S, Ricker, M, Hegger, J (2019) Biegebemessungsmodell mit einer geschlossenen und iterativen Lösung für Textilbetonbauteilen. Beton- und Stahlbeton 115:218-230. doi: 10.1002/best.201900086

33. Bielak J, Spelter A, Will N, Claßen M (2018) Verankerungsverhalten textiler Bewehrungen in dünnen Betonbauteilen. Beton-und Stahlbetonbau, 113(7):515-524. doi: 10.1002/best.201800013

34. Bielak J, Adam V, Hegger J, Classen M (2019) Shear capacity of textile-reinforced concrete slabs without shear reinforcement. Applied Sciences 9(7):1382. doi: 10.3390/app9071382

35. Stark A, Classen M, Knorrek C, Camps B, Hegger J (2018) Sandwich panels with folded plate and doubly curved UHPFRC facings. Structural Concrete 19(6):18511861. doi: 10.1002/suco.201700288

36. Stark A, Classen M, Hegger J (2019) Bond behaviour of CFRP tendons in UHPFRC. Engineering Structures 178:148-161. doi: 10.1016/j.engstruct.2018.10.002

37. Herbrand M, Adam V, Classen M, Kueres D, Hegger J (2017) Strengthening of existing bridge structures for shear and bending with carbon textile-reinforced mortar. Materials 10(9):1099. doi: 10.3390/ma10091099

38. Classen M (2020) Shear Crack Propagation Theory (SCPT) - The mechanical solution to the riddle of shear in RC members without shear reinforcement. Engineering Structures 210:110207. doi: 10.1016/j.engstruct.2020.110207

Author Contributions: Conceptualization and planning, Sergej Rempel and Marcus Ricker; Computation, analysis, and interpretation of the data, Sergej Rempel, Marcus Ricker and Tânia Feiri; Drafting, Marcus Ricker and Tânia Feiri; Critical revision, Sergej Rempel and Marcus Ricker. All authors have read and agreed to the published version of the manuscript. Acknowledgments: The authors thank the two companies: Solidian GmbH and FTAForschungsgesellschaft für Textiltechnik Albstadt GmbH for their support in carrying out the fibre strand tensile tests and providing the textile reinforcements.

Conflicts of Interest: The authors declare no conflict of interest. 